\title{
Dispersion effect in formic acid oxidation on PtAu/C nanocatalyst prepared by water-in-oil microemulsion method
}

M.N. Krstajić Pajića , S.I. Stevanovićb, V.V. Radmilovićc, A. Gavrilović-Wohlmuther ${ }^{\mathrm{d}}$, P. Zabinski ${ }^{\mathrm{e}}$, N.R. Elezović ${ }^{f}$ V.R. Radmilovića, ${ }^{a, g}$, S.Lj. Gojkovića ${ }^{a}$, V.M. Jovanovićc $c^{b, *}$

${ }^{a}$ Faculty of Technology and Metallurgy, University of Belgrade, Karnegijeva 4, 11000 Belgrade, Serbia

${ }^{\mathrm{b}}$ Department of Electrochemistry, ICTM, University of Belgrade, Njegoševa 12, 11000 Belgrade, Serbia

${ }^{\mathrm{c}}$ Innovation Center, Faculty of Technology and Metallurgy, University of Belgrade, Karnegijeva 4, 11000 Belgrade, Serbia

${ }^{\mathrm{d}}$ CEST-Centre of Electrochemical Surface Technology GmbH, Viktor-Kaplan Strasse 2, 2700 Wiener Neustadt, Austria

${ }^{\mathrm{e}}$ AGH University of Science and Technology, Faculty of Non-Ferrous Metals, al. Mickiewicza 30, 30-059 Krakow, Poland

${ }^{\mathrm{f}}$ Institute for Multidisciplinary Research, University of Belgrade, Kneza Višeslava 1, 11030 Belgrade, Serbia

${ }^{\mathrm{g}}$ Serbian Academy of Sciences and Arts, Knez Mihailova 35, 11000 Belgrade, Serbia

\section{A R T I C L E I N F O}

\section{Keywords:}

PtAu nanoparticles

Microemulsion method

Formic acid electrooxidation

Methanol electrooxidation

\begin{abstract}
A B S T R A C T
Low loading PtAu nanoparticles supported on high area carbon were synthesized by water-in-oil microemulsion method and examined for formic acid and methanol oxidation. Prepared catalyst powder was characterized by Xray diffraction (XRD), transmission electron microscopy (TEM), energy-dispersive X-ray spectroscopy (EDS) and $\mathrm{X}$-ray photoelectron spectroscopy (XPS). These techniques revealed that the catalyst contains rather agglomerated quasi-spherical particles, $\sim 4 \mathrm{~nm}$ diameter, composed of a solid solution of Pt and Au with only $\sim 4$ at $\%$ of Au. In spite of such low Au content, both onset and peak potentials for CO oxidation are shifted some $150 \mathrm{mV}$ to more positive values in comparison to Pt synthesized in the same manner due to stronger binding of $\mathrm{CO}$ as a result of notable electronic effect. It is important that this small quantity of Au also significantly influences oxidation of formic acid promoting direct path and suppressing indirect path in formic acid oxidation in a degree as expected by a much larger quantity of Au. Such improvement could be due exclusively by ensemble effect of high number of small Pt domains which formation could be possible only by very fine dispersion of such low Au quantity. High number of small Pt domains is corroborated by lower activity for methanol oxidation in comparison to Pt catalyst synthesized by the same procedure. These results emphasize the importance of the Au dispersion on the surface of Pt over its quantity in PtAu catalyst with regards to both, the ensemble and the electronic effects.
\end{abstract}

\section{Introduction}

Among a variety of fuel cells (phosphoric acid, solid acid, alkaline, solid oxide etc.) polymer electrolyte fuel cells (PEMFC) are attracting considerable attention as power generators for portable devices [1]. In these devices, chemical energy is converted to electrical by oxidation of hydrogen or small organic molecules like methanol, formic acid, ethanol, etc. Direct formic acid fuel cells (DFAFC) draw increasing interest due to their advantages over direct methanol fuel cells (DMFC) due to favorable characteristics such as smaller crossover flux through a membrane, less positive onset potential of its oxidation as well as safety [1]. Among pure metals, platinum (Pt) and palladium (Pd) are considered as most effective catalysts for the oxidation of formic acid. However, both Pt and Pd exhibit significant disadvantages. Catalytic activity of Pt is significantly reduced at low potentials due to $\mathrm{CO}$ poisoning from dehydration (indirect) path in $\mathrm{HCOOH}$ oxidation. On the other hand, Pd shows much higher initial activity in comparison to Pt but significantly deactivates during time [2] and is not stable in acid solutions [3]. Besides, palladium price has recently become even higher that Pt. The abundance of Pd in Earth's crust is lower than Pt, as well. Nevertheless, Pt has been more investigated for this reaction. In order to improve the electrocatalytic activity and suppress poisoning by $\mathrm{CO}$, various metals have been combined with $\mathrm{Pt}$ in form of alloys and intermetallics [4,5], core-shell structures [6,7] or adatoms [8,9]. The influence of other metal on the electrocatalytic activity of Pt could be exhibited via the electronic effect, bi-functional mechanism and the ensemble effect. The electronic effect is based on the electronic interaction between Pt and the added metal which results in changes of

\footnotetext{
* Corresponding author.

E-mail address: vlad@tmf.bg.ac.rs (V.M. Jovanović).
} 
binding energies of adsorbed species on Pt and contributes to improved activity $[4,10,11]$. The bi-functional mechanism provides enhanced activity of Pt based bi-metallic catalysts due to easier adsorption of $\mathrm{OH}$ on the added metal and thus oxidation of $\mathrm{CO}$ adsorbed on Pt at significantly lower potentials compared to pure Pt [12]. While these two effects influence oxidative removal of adsorbed CO i.e. indirect-dehydration path, the ensemble effect promotes the dehydrogenation-direct path and suppresses CO poisoning [13,14]. Namely, Kristian and coworkers [13] studied formic acid oxidation on Pt decorated Au particles and from their results they inferred that dehydration and $\mathrm{CO}$ formation decreased with decreasing the adjacent Pt atoms, i.e. with decrease of Pt coverage on Au surface. Furthermore Cuesta et al. [14], based on their study of $\mathrm{HCOOH}$ oxidation at Pt(111) single crystal modified by adsorbed $\mathrm{CN}$, concluded that dehydration of $\mathrm{HCOOH}$ to adsorbed $\mathrm{CO}$ on Pt requires at least three contiguous atoms, while direct $\mathrm{HCOOH}$ oxidation to $\mathrm{CO}_{2}$ takes place on a smaller atomic assembles.

In order to enhance electrocatalytic activity and lower poisoning by $\mathrm{CO}$, various metals such as $\mathrm{Bi}, \mathrm{Pb}, \mathrm{Co}, \mathrm{Pd}$ and $\mathrm{Au}$ [15-19] have been combined with Pt. The addition of Au seems to be the most promising due to its high chemical stability [20]. PtAu systems have been proven as good catalysts for $\mathrm{HCOOH}$, and are widely investigated since the work of Rach and Heitbaum [21]. It is possible to synthesize bimetallic PtAu nanoparticles by various synthesis procedures [22-26]. One of the commonly used approaches is chemical reduction of precursor salts by $\mathrm{NaBH}_{4}$ as a reducing agent, in the presence of sodium citrate [22]. Another example is microwave assisted polyol method, that has also been used to prepare bimetallic nanoparticles supported on high area carbon materials [23-25]. Microwave irradiation was also employed with chemical reduction of precursor salts with trisodium citrate dehydrate (TSC), as a more environmentally acceptable approach [10]. Oko and co-workers however, produced PtAu nanoparticles by a pulsed laser ablation method [26].

In our research we have used a water-in-oil microemulsion method that has not been used for this system so far. Microemulsions are used for production of nanoparticles because they can provide a good control of particle shape and size. We have recently synthesized Pt nanoparticles supported on high area carbon by this procedure [27]. In the present study, the intention was to prepare low loading PtAu catalyst without changing any synthesis steps from our previous work, but simply adding Au precursor into the system. The PtAu/C catalyst prepared by this procedure contained only $\sim 4$ at $\%$ of Au. Nevertheless, the catalyst exhibited activity for formic acid and CO oxidation similar to that of PtAu catalysts, with drastically higher Au content, described in literature [20]. This finding underlines the importance of Au dispersion on the surface of Pt over its quantity for the significance of both, the electronic and the ensemble effects.

\section{Experimental}

\subsection{Preparation of the catalysts}

Simultaneous water-in-oil microemulsion method was applied in order to synthesize PtAu catalyst. Equal volumes $(0.05 \mathrm{M})$ of precursors $\mathrm{H}_{2} \mathrm{PtCl}_{6}$ and $\mathrm{HAuCl}_{4}$ present in the water phase of this system fwater|polyethyleneglycol-dodecylether (BRIJ $\left.{ }^{\circ} 30\right) \mid n$-heptane\}, were reduced by $\mathrm{NaBH}_{4}$ with BRIJ 30 used as a surfactant. Water to surfactant molar ratio was 3.8 , while the amount of surfactant in microemulsion was 16.5 vol. \% of the total volume of the microemulsion. Formed PtAu nanoparticles were supported on Vulcan XC-72R after the completion of the reduction reaction. Nominal content of Pt in catalyst powders was targeted to be $10 \mathrm{wt} \%$. Acetone was added in the final step in order to cause precipitation, and the precipitate was subsequently washed thoroughly with ultra-pure water (Millipore, $18 \mathrm{M} \Omega \mathrm{cm}$ ) on a membrane filter, using a vacuum pump, and dried in $\mathrm{N}_{2}$ atmosphere at $170^{\circ} \mathrm{C}$ for $3 \mathrm{~h}$.

\subsection{Characterization of the catalysts}

X-ray diffraction (XRD) characterization of the catalyst was performed on an X-Pert powder diffractometer (PANalytical, Netherlands) using $C u K_{\alpha}$ radiation in Bragg-Brentano geometry at $40 \mathrm{kV}$ and $30 \mathrm{~mA}$. The measurements were conducted in a step scan mode in $0.05^{\circ}(2 \theta)$ intervals with a measuring time of $30 \mathrm{~s} / \mathrm{step}$. The TOPAS V3 general profile and structure analysis software for powder diffraction data was used for the Rietveld refinement procedure [28].

The supported catalyst was analyzed on a FEI TITAN ${ }^{3}$ Themis 60-300 double aberration corrected transmission electron microscope (TEM) equipped with the Super-X energy dispersive spectrometry (EDS) system controlled with Bruker Esprit software. Samples were drop cast onto Holey carbon grids and investigated at $200 \mathrm{kV}$ operating voltage by CTEM (conventional transmission electron microscopy) and STEM (scanning transmission electron microscopy).

The X-ray photoelectron spectroscopy (XPS) analysis of the sample was carried out in an ultrahigh vacuum system $\left(3 \cdot 10^{-10} \mathrm{mbar}\right)$ equipped with hemispherical analyzer (SES R4000, Gammadata Scienta). The MgKa source of incident energy of $1256.6 \mathrm{eV}$ was applied to generate core excitation. The spectrometer was calibrated according to ISO15472:2001. The energy resolution of the system, measured at full width at half maximum (FWHM) for $\mathrm{Ag} 3 \mathrm{~d} 5 / 2$ excitation line, was $0.9 \mathrm{eV}$. Prior to the analysis, the powder sample was pressed into indium foil. The analysis area of prepared sample was $\sim 3 \mathrm{~mm}^{2}$. Neither gas release nor changes in the sample composition were observed during the measurements. The CasaXPS 2.3.12 software was used for analysis of the XPS spectra. No charging was observed for the studied sample and, therefore no additional calibration of the spectra energy scale was applied. In the spectra, the background was approximated by a Shirley profile. The spectra deconvolution into a minimum number of components was done by application of the Voigt-type line shapes (70:30 Gaussian/Lorentzian product). The analytic depth of the XPS method was estimated to be $10.2 \mathrm{~nm}$. The calculations were performed with QUASES-IMFP-TPP2M Ver 2.2 software according to an algorithm proposed by Tanuma et al. [29]. This estimation takes into account $95 \%$ of photoelectrons escaping from the surface. The experimental error of the XPS analysis was $\pm 3 \%$.

\subsection{Electrochemical measurements}

All electrochemical experiments were performed at room temperature in a three-electrode-compartment electrochemical cell with a Pt wire as the counter electrode and a bridged saturated calomel electrode (SCE) as the reference one. The working electrode was a thin layer of Nafion-impregnated $\mathrm{PtAu} / \mathrm{C}$ catalyst applied on a polished glassy carbon disk electrode. The thin layer was obtained from the suspension of the catalyst in a mixture of $1 \mathrm{ml}$ water and $50 \mu \mathrm{l}$ of $5 \%$ aqueous Nafion solution. After dispersion in an ultrasonic bath, the suspension was placed on the electrode and dried at room temperature. The catalyst loading was $\sim 20 \mu \mathrm{g} / \mathrm{cm}^{2}$ for Pt/C and $\sim 5 \mu \mathrm{g} / \mathrm{cm}^{2}$ for PtAu/C.

The electrocatalytic activity of $\mathrm{PtAu} / \mathrm{C}$ catalyst was studied for the oxidation of adsorbed $\mathrm{CO}$, formic acid and methanol. $\mathrm{CO}$ was adsorbed at the electrode surface from $\mathrm{CO}$ saturated $0.5 \mathrm{M} \mathrm{H}_{2} \mathrm{SO}_{4}$ solution while keeping the electrode potential at $-0.2 \mathrm{~V}$ for $15 \mathrm{~min}$. Subsequently, the electrode was transferred into the cell containing $\mathrm{N}_{2}$ saturated $0.5 \mathrm{M}$ $\mathrm{H}_{2} \mathrm{SO}_{4}$ and the adsorbed $\mathrm{CO}$ was electrochemically oxidized at a sweep rate of $50 \mathrm{mV} / \mathrm{s}$. Three subsequent voltammograms were recorded to verify that $\mathrm{CO}$ has been completely removed. The oxidation of formic acid was examined in a solution containing $0.5 \mathrm{M} \mathrm{H}_{2} \mathrm{SO}_{4}$ and $0.5 \mathrm{M}$ $\mathrm{HCOOH}$. The latter $(\mathrm{HCOOH})$ was added to the supporting electrolyte solution while holding the electrode potential at $-0.2 \mathrm{~V}$. The potential was then cycled up to $0.9 \mathrm{~V}$ at sweep rate of $50 \mathrm{mV} / \mathrm{s}$. The electrocatalytic activity of PtAu catalysts for methanol oxidation reaction was investigated in a solution containing $0.5 \mathrm{M} \mathrm{H}_{2} \mathrm{SO}_{4}$ and $0.5 \mathrm{M} \mathrm{CH}_{3} \mathrm{OH}$, using the same procedure as in the case of $\mathrm{HCOOH}$. Long-term stability 
of the catalyst for formic acid oxidation (FAOR) and methanol oxidation (MOR) was tested during 100 cycles in the same potential range. Chronoamperometric measurements were recorded for $\mathrm{HCOOH}$ oxidation after immersion of the freshly prepared electrode in the solution at $0.2 \mathrm{~V}$ and holding the electrode at that potential for $30 \mathrm{~min}$. Each of the reactions was studied at freshly prepared surfaces, which featured similar basic voltammograms.

The electrochemical surface area (ECSA) of the catalyst was determined from the Pt-oxide reduction peak using a charge of $440 \mathrm{C} / \mathrm{cm}^{2}$ for a Pt-oxide monolayer [20,30]. The currents are normalized by ECSA.

All the solutions were prepared from Merck p.a. reagents with high purity water (Millipore, $18 \mathrm{M} \Omega \mathrm{cm}$ resistivity). The electrolytes were purged with purified $\mathrm{N}_{2}$ prior to each experiment. AUTOLAB potentiostat/galvanostat PGStat $128 \mathrm{~N}$ (MetrohmAutolab B.V., The Netherlands) was used in electrochemical experiments.

\section{Results and discussion}

\subsection{Physicochemical characterization of the catalysts}

Carbon supported PtAu (PtAu/C) catalyst, synthesized by water-inoil method was analyzed by XPS and the results (presented in Fig. 1) confirmed the presence of both metals.

The convoluted platinum spectrum Pt $4 \mathrm{f}$ is mainly composed of metallic Pt with only $<6 \%$ related to alloy or intermetallic compounds (peak $A$ at $\sim 71 \mathrm{eV}$ ). Shift of binding energy (BE) for peak $B$ to higher values ( $\mathrm{B}$ at $\sim 72 \mathrm{eV}$ ) indicates that metallic $\mathrm{Pt}$ is in the form of nanoparticles. Peak C (at $\sim 73 \mathrm{eV}$ ) reveals the presence of $\mathrm{Pt}^{2+}-\mathrm{OH}$ i.e. $\mathrm{Pt}$ in the vicinity of $-\mathrm{OH}$ and/or $-\mathrm{COOH}$ species. Regarding the deconvoluted $\mathrm{Au} 4 \mathrm{f}$ XPS spectra, peak A (at $\sim 84.5 \mathrm{eV}$ ) indicates metallic Au while a slight shift of $\mathrm{BE}$ for maximum $\mathrm{Au} 4 \mathrm{f}_{7 / 2}$ ( $\mathrm{A}^{\prime}$ at $\sim 88 \mathrm{eV}$ ), at higher $\mathrm{BE}$ values confirms the presence of very small particles. Based on the intensities of the XPS peaks of the catalyst, the surface and near surface atomic ratio $\mathrm{Pt}: \mathrm{Au}$ is $94: 6$ at $\%$.

XRD patterns of the PtAu/C and $\mathrm{Pt} / \mathrm{C}$ catalysts, prepared by the same method, are shown in Fig. 2.

The reference spectra of $\mathrm{Au}, \mathrm{Pt}$ and Pt-Au alloys based on ICDD-PDF cards are presented as well. The diffraction pattern of the latter catalyst shows the main characteristic peaks of the face centered cubic, $f c c$, Pt crystalline structure ([03-065-2868] ICDD-PDF) with the lattice parameter of $0.3928 \mathrm{~nm}$ and the average particle size of $\sim 2 \mathrm{~nm}$. Similar peaks but slightly shifted to lower $2 \theta$ angles are observed in the XRD pattern of the PtAu/C catalyst. Since the peak positions of metallic Pt, metallic Au and Pt-Au alloys (Fig. 2 ICDD cards) are practically in the same place, it is difficult to determine whether PtAu catalyst consists of pure Pt and PtAu alloy or it is a solid solution of Au in Pt. However, diffuse peaks around $70^{\circ}$ and $80^{\circ}$ suggest that a solid solution of Pt and Au rather than pure Pt and alloy is in question. Although the average

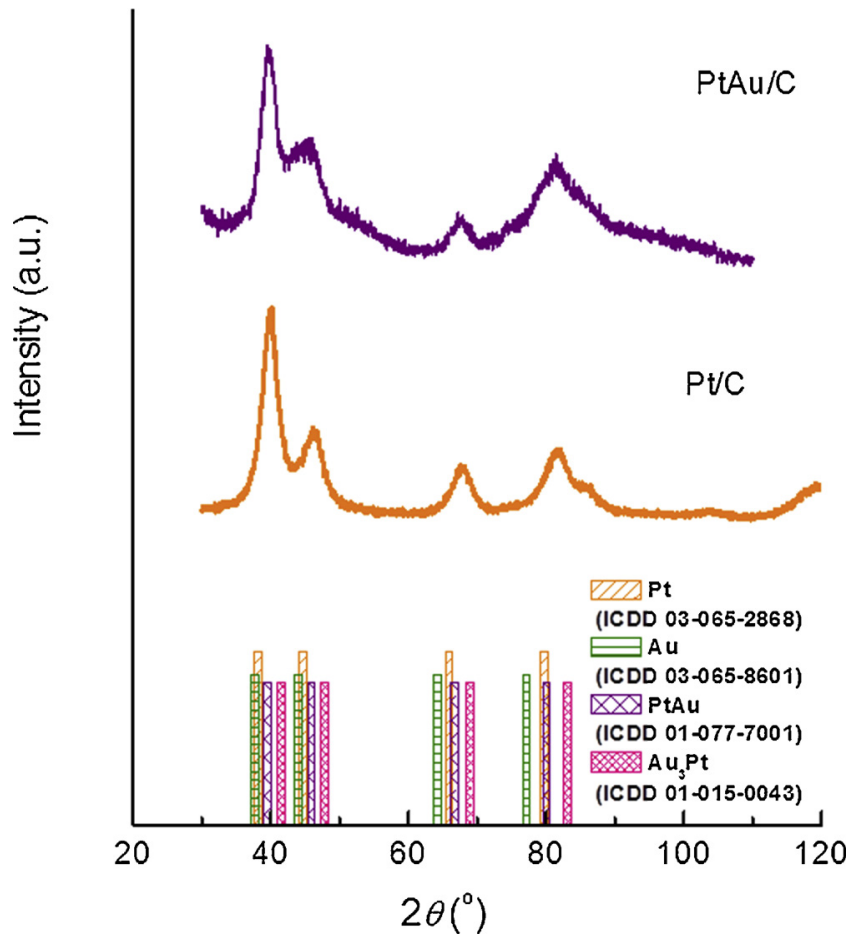

Fig. 2. XRD patterns of the supported Pt/C and PtAu/C catalysts.

particle size is the same as for $\mathrm{Pt} / \mathrm{C}(\sim 2 \mathrm{~nm})$ catalyst, wider peaks indicate the presence of even smaller particles. The lattice parameter of PtAu particles was calculated to be $a=0.3934 \mathrm{~nm}$. Using 311 peak and Vegard's law, composition of the particles was calculated to be 97.18 at $\%$ of Pt and 2.82 at $\%$ of Au (Supplementary material).

EDS maps (Fig. 3), obtained in scanning transmission electron microscopy (STEM) high angle annular dark field (HAADF) mode, revealed elemental composition of the particles to be in the atomic ratio (at\%) Pt:Au = 96:4. Although this is in a good agreement with calculations via lattice parameter from peaks in XRD pattern (where the content of Au was calculated to be $\sim 3$ at $\%$ ), EDS analysis gave insight into the non-uniform distribution of $\mathrm{Au}$ in the catalyst. Content of $\mathrm{Au}$ ranged from $\sim 1$ at $\%$ for small particles to $\sim 10$ at $\%$ for particle clusters. The origin of this is most likely the randomness of material distribution during processing. Nevertheless, analyzing these EDS maps, a very fine dispersion of Au can be observed. It should be mentioned that this low quantity of Au means significant loss of the metal during synthesis making this catalyst low loading (instead of nominal $10 \mathrm{wt} \%$ it is $\sim 5 \mathrm{wt} \%$ ). The size of these particles could be the reason for the loss of Au. We suppose that the reduction rates of Pt and Au by strong
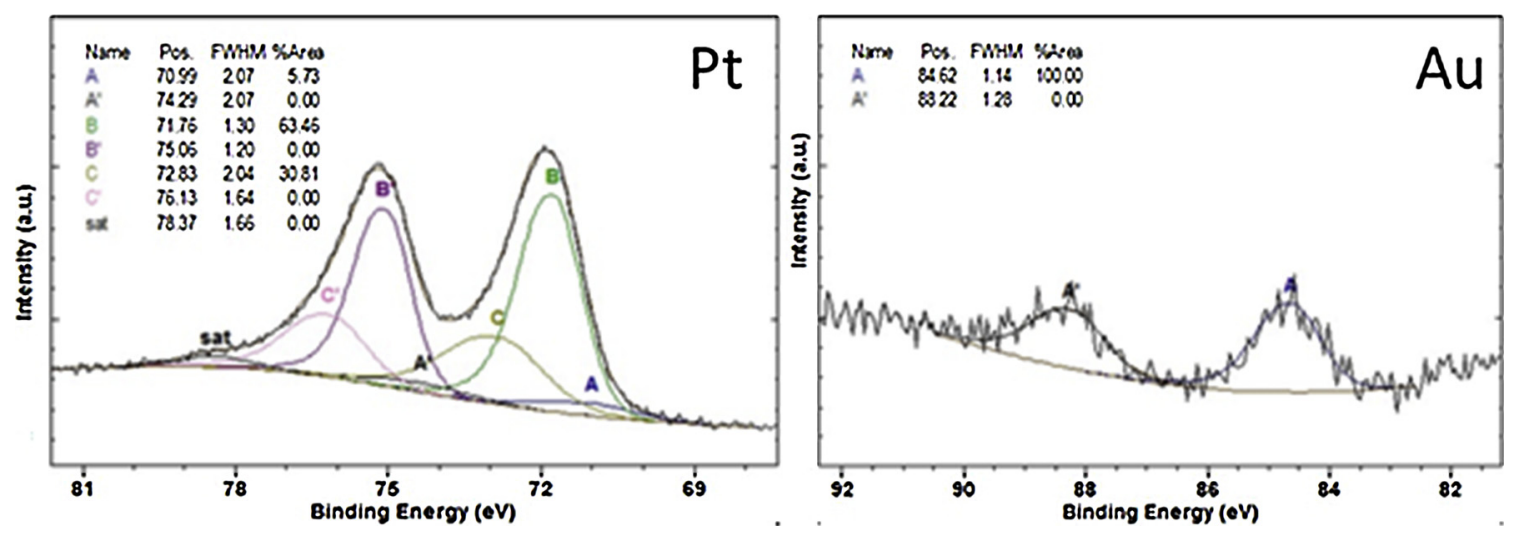

Fig. 1. Pt 4f and Au 4f XPS spectra of PtAu particles supported on carbon substrate with noted characteristic peaks. 

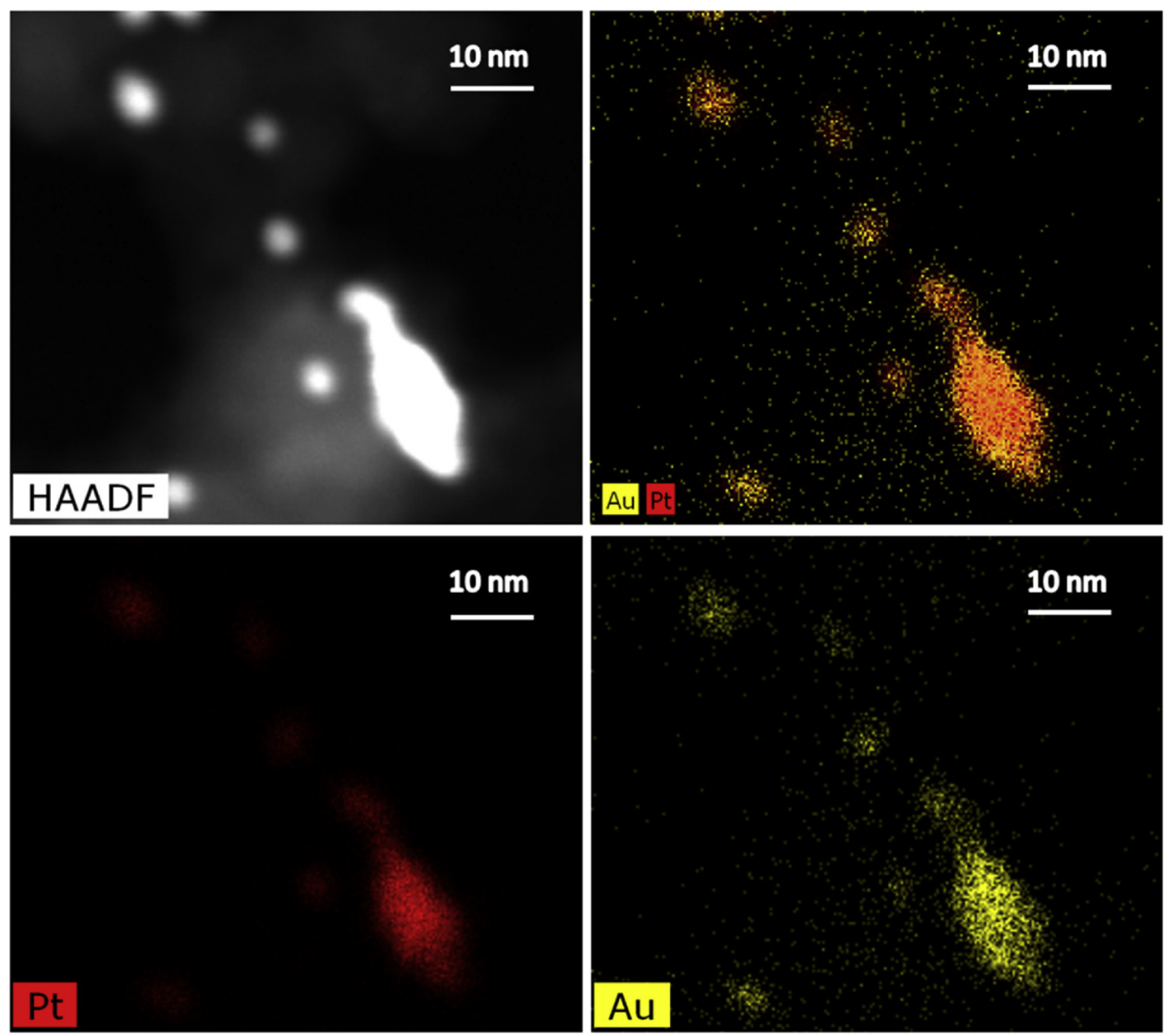

Fig. 3. HAADF STEM image of PtAu particles and clusters on carbon support and a composite EDS map of both, Pt and Au, as well as corresponding EDS maps noting distribution of Pt and Au.

reducing agent $\mathrm{NaBH}_{4}$ and nuclei formation and their growth in waterin-oil environment are quite different which results in the creation of very small Au particles, a part of which do not succeed to combine with Pt and are washed out from the catalyst.

The value of $\mathrm{Au}$ present on the surface (more precisely in near surface region) based on XPS analysis ( $~ 6$ at $\%$ ) is higher than 4 at $\%$ in the bulk of the catalyst, most likely due to easy segregation of Au upon thermal treatment of the catalyst (at $170{ }^{\circ} \mathrm{C}$ for $3 \mathrm{~h}$ in $\mathrm{N}_{2}$ atmosphere) in the course of synthesis.

Transmission electron micrographs of PtAu/C catalyst disclosed the presence of individual particles as well as agglomerates (Fig. 4A), while high resolution transmission electron micrographs, HRTEM, (Fig. 4B) clearly indicated that these particles are of $f c c$ type whose orientation is close to $\{110\}$ i.e. Fast Fourier transforms (FFTs) show planes of $\{111\}$ and $\{200\}$ types. Average particle size, excluding agglomerates from the measurement, was calculated from a fairly large number of particles in TEM images and the value was $4.8 \pm 1.4 \mathrm{~nm}$ (noted by histogram in Fig. 4C). For comparison, average particle size of Pt/C catalyst synthesized by the same procedure, was calculated to be $3.7 \pm 1.8 \mathrm{~nm}$. From these images we can presume that co-precipitation of $\mathrm{Au}$ and $\mathrm{Pt}$ has occurred as both elements are present in the same positions in the structure. Additionally, FFTs of other particles in this catalyst do not show the presence of "super reflections" which are indicative of an ordered structure. This means that this catalyst is a solid solution of Au in Pt.

Having in mind all of the analysis above of PtAu/C catalyst synthesized by water-in-oil method, we can assume that the catalyst is a solid solution of $\mathrm{Au}$ in $\mathrm{Pt}$ with $\sim 4$ at $\%$ of uniformly and very finely
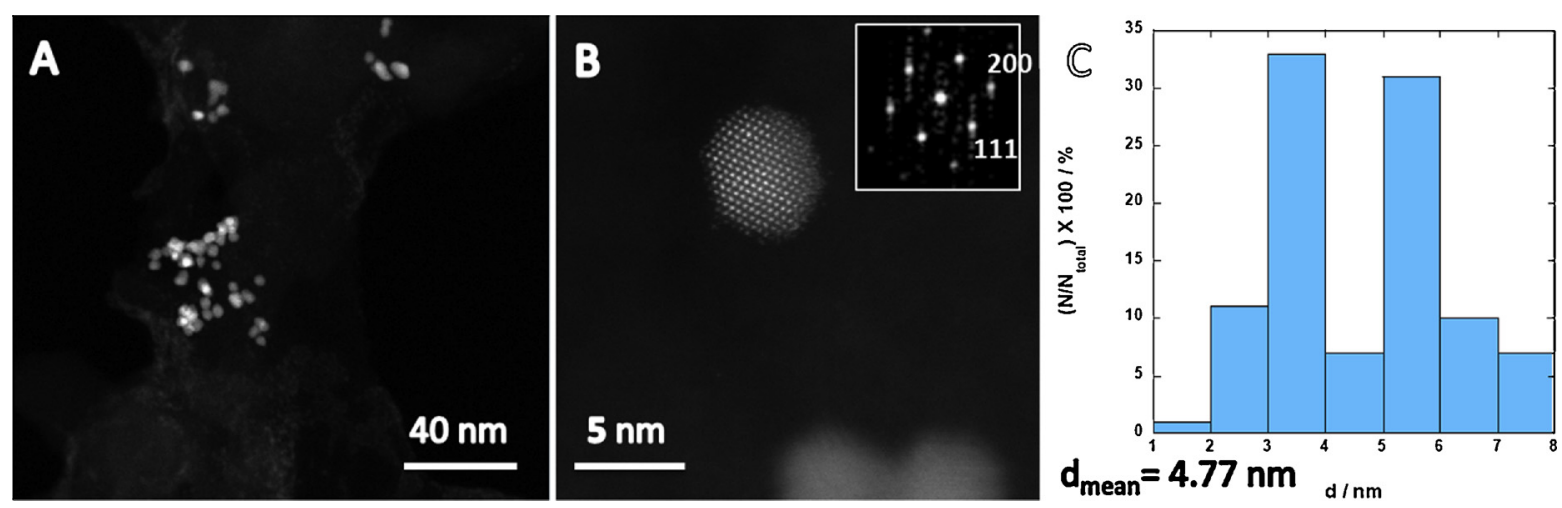

Fig. 4. Low magnification TEM image (A), high resolution TEM image (B) with inset representing FFT of PtAu particle, and particle size distribution of PtAu/C catalyst (C). 


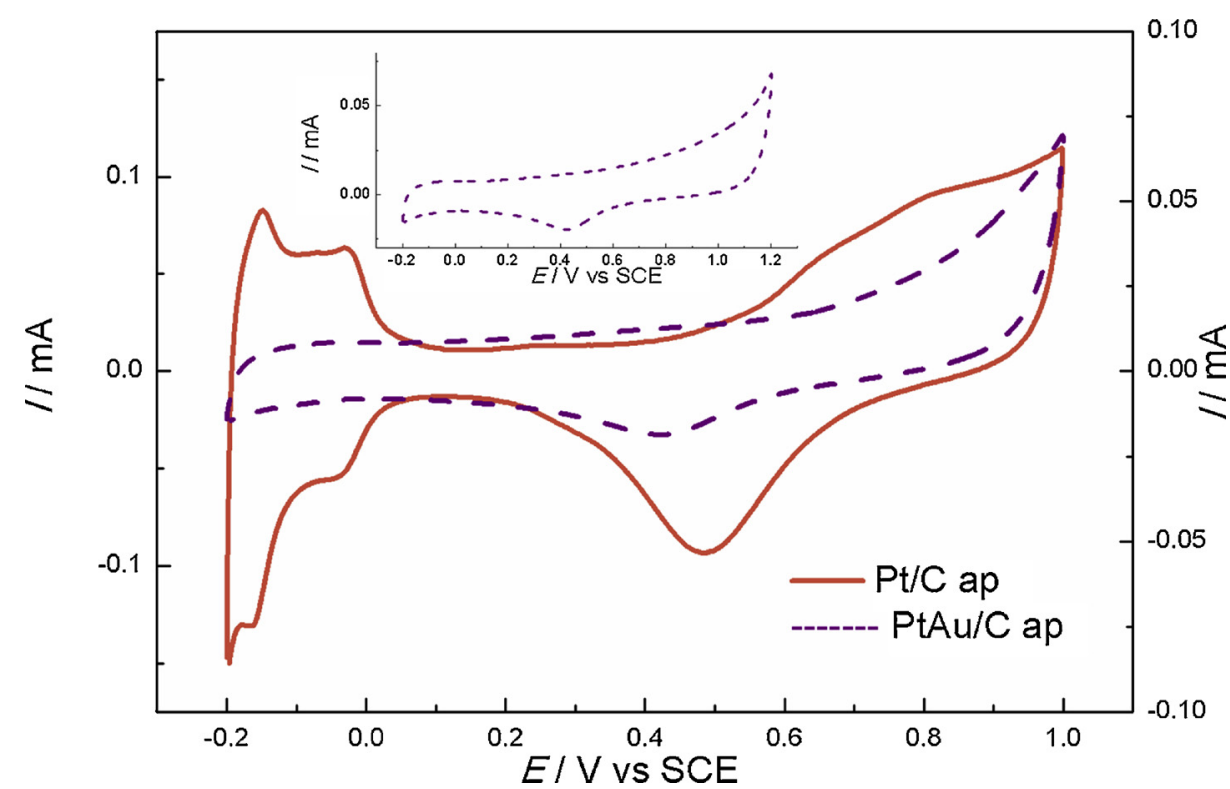

Fig. 5. Cyclic voltammograms of as-prepared (ap) $\mathrm{Pt} / \mathrm{C}$ and $\mathrm{PtAu} / \mathrm{C}$ catalysts in $0.5 \mathrm{M} \mathrm{H}_{2} \mathrm{SO}_{4}(\mathrm{v}=50 \mathrm{mV} / \mathrm{s})$. Inset: Cyclic voltammogram of PtAu/C in extended positive potential limit.

dispersed Au.

\subsection{Electrochemical characterization of the catalysts}

The PtAu/C catalyst was characterized by cyclic voltammetry and oxidation of $\mathrm{CO}_{\mathrm{ads}}$ and compared with $\mathrm{Pt} / \mathrm{C}$ catalyst prepared in the similar manner. An initial scan of each as-prepared catalyst, without any electrochemical treatment, is presented in Fig. 5.

Analyzing these voltammograms it is noticeable that as-prepared $\mathrm{Pt} / \mathrm{C}$ exhibits characteristic peaks that are fingerprints of the hydrogen underpotential deposition $\left(\mathrm{H}_{\mathrm{UPD}}\right)$ on $\{110\}$ atomic positions and atomically ordered sites on $\{100\}$ surfaces [31,32], well defined double-layer region, onset of Pt oxide formation at $\sim 0.5 \mathrm{~V} / \mathrm{SCE}$ and $\mathrm{Pt}$ oxide reduction at $0.5 \mathrm{~V} / \mathrm{SCE}$. In the case of as-prepared $\mathrm{PtAu} / \mathrm{C}$ catalyst, the initial scan looks completely different, especially having in mind the low Au content suggesting that the nanoparticles should have a $\mathrm{Pt}$ rich surface. The region of $\mathrm{H}_{\mathrm{ads}} / \mathrm{H}_{\mathrm{des}}$ (hydrogen adsorption/hydrogen desorption) is completely shapeless, onset of oxide formation is shifted for $\sim 100 \mathrm{mV}$ to more positive potentials and the potential of oxide reduction is shifted for $\sim 70 \mathrm{mV}$ to lower values in comparison to $\mathrm{Pt} / \mathrm{C}$. Suppression of $\mathrm{H}_{\mathrm{UPD}}$ region as well as the positive shift of Pt oxide formation and the negative shift of its reduction was recorded for any Pt-Au surface $[10,14]$. The extent of these changes depends on the Pt:Au ratio being more pronounced for lower ratio i.e. with increasing Au coverage on Pt. Regarding our catalyst this should signify high Au coverage on the catalyst surface. The direction of potential shifts in the region of $\mathrm{Pt}$ oxide formation/reduction for $\mathrm{PtAu} / \mathrm{C}$ catalyst signifies stronger adsorption of $\mathrm{OH}$ species and oxygen bonding to Pt which is a consequence of modified chemical properties and electronic structure of $\mathrm{Pt}$ as the result of Pt-Au interaction. Modification of chemical properties is caused by change of average bond lengths between metal atoms due to the strain effect as well as by heterometallic bonding interaction i.e. the ligand effect that results in changes of electronic structure of the surface. These effects are well explained in the case of thin films [33-35]. Strain and the ligand effect are cumulative and alter the width of $d$-band. As the Au lattice constant is larger than Pt lattice constant due to such mismatch Pt lattice with some atoms replaced by $\mathrm{Au}$ atoms is under tensile strain. The Pt $d$-band width is narrower in comparison to pure Pt thereby its energy increases i.e. center of the $d$ band moves to the Fermi level in order to keep constant the overall $d$ band filling. The ligand effect appears because of the heterometallic bonding between Pt and Au which also causes constriction of $d$-band i.e. an increase of $d$-band energy [31]. This $d$-band energy increase leads to stronger bonding between Pt and oxygen which in turn leads to a negative shift of potential of Pt oxide reduction. According to literature $[10,20,36]$, the potential of Pt oxide reduction shifts to lower values as Au content in PtAu catalyst increases. This enlarges the reduction peak of Au oxide which confirms the presence of Au at the surface and was recorded at $1.2 \mathrm{~V}$ vs reversible hydrogen electrode (RHE). However, in the case of the PtAu/C catalyst, in spite of high positive potential limit, no sign of the Au presence is recorded (inset in Fig. 5), although Pt oxide reduction peak is significantly shifted to lower potentials which is possible only with intimate contact between Pt and Au. Bearing in mind the very small Au content, it can be assumed that no sign of Au on CV is recorded (Fig. 5) due to a very fine dispersion of small Au particles what correlates with high Au coverage on the surface.

Additional characterization of the catalysts was performed by the oxidation of $\mathrm{CO}_{\mathrm{ads}}$, the reaction extremely sensitive to surface structure. Stripping curves for $\mathrm{CO}_{\mathrm{ads}}$ on the as-prepared $\mathrm{Pt} / \mathrm{C}$ and $\mathrm{PtAu} / \mathrm{C}$ are presented in Fig. 6.

Oxidation of $\mathrm{CO}_{\text {ads }}$ on $\mathrm{Pt} / \mathrm{C}$ surfaces commences at $0.45 \mathrm{~V} / \mathrm{SCE}$ and proceeds through a sharp peak with a maximum at $\sim 0.6 \mathrm{~V} / \mathrm{SCE}$. For the bimetallic $\mathrm{PtAu} / \mathrm{C}$ catalyst, the reaction proceeds through an even

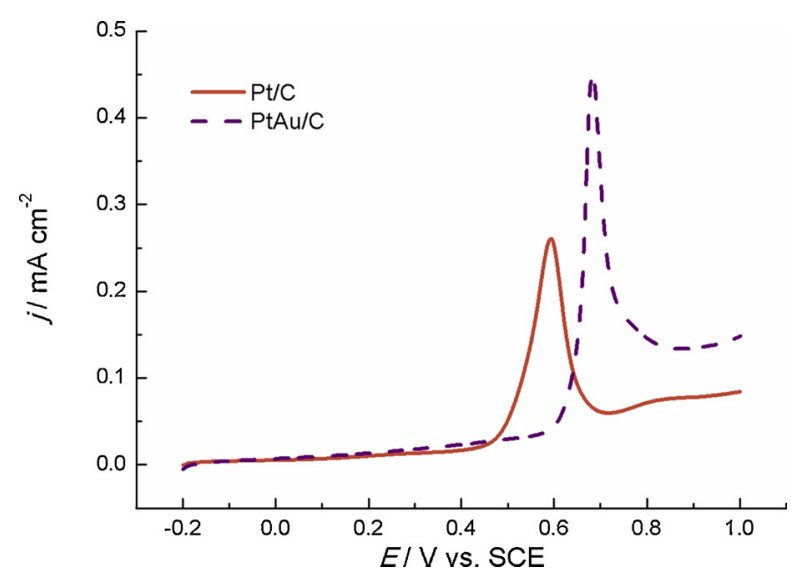

Fig. 6. $\mathrm{CO}_{\mathrm{ads}}$ stripping curves for as-prepared $\mathrm{Pt} / \mathrm{C}$ and $\mathrm{PtAu} / \mathrm{C}$ catalysts in $0.5 \mathrm{M} \mathrm{H}_{2} \mathrm{SO}_{4}, \mathrm{v}=50 \mathrm{mV} / \mathrm{s}$. 
narrower peak and both, onset and peak potential are shifted for $\sim 150 \mathrm{mV}$ to more positive values. This positive potential shift is due to the stronger adsorption of $\mathrm{CO}$ on $\mathrm{Pt}$ when in contact with $\mathrm{Au}$, which is, as already explained in the case of Pt oxide reduction, due to the increase in energy of $d$-band triggered by tensile strain and the ligand effect. In addition, stronger adsorption of $\mathrm{OH}$, revealed from higher potentials for Pt oxide formation (Fig. 5) could also hinder oxidation of $\mathrm{CO}_{\text {ads. }}$. Based on the literature data $[10,20,31,36,37], \mathrm{CO}_{\mathrm{ads}}$ oxidation potential is shifted to more positive values as the Au content increases and more Pt atoms are in direct contact with Au. Simultaneously, the width of the $\mathrm{CO}_{\text {ads }}$ stripping peak increases as the fraction of Pt on the surface of PtAu decreases which is ascribed to low reactant mobility [31]. However, according to Arenz et al. [38], oxidation of $\mathrm{CO}_{\mathrm{ads}}$ is controlled by the number of defects rather than by their mobility i.e. for surfaces with fewer defects, the stripping peak is narrower and is positioned at higher potential. Recently, Farias et al. [39] after studying CO oxidation on Pt particles (cubic and octahedral shaped, with $\{100\}$ and $\{111\}$ facets, respectively) concluded that, when formed, the $\mathrm{CO}_{\mathrm{ads}}$ layer remained motionless during oxidation. Having this in mind, it can be assumed that the $\mathrm{CO}_{\mathrm{ads}}$ oxidation on the $\mathrm{PtAu} / \mathrm{C}$ catalyst at such a high positive potential value through a narrow peak is due to highly dispersed $\mathrm{Au}$ on the surface of PtAu particles and fewer defects on $\mathrm{Pt}$ domains.

\subsection{Electrocatalytic activity of the catalysts}

The activity of PtAu/C catalyst was tested by FAOR and compared with the activity of Pt/C catalyst as shown in Fig. 7. Potentiodynamic curve recorded for Pt/C catalyst has well-established shape for FAOR on Pt with two peaks in forward and one in backward direction, revealing the duel path mechanism. Hence, the reaction commences at the end of $\mathrm{H}_{\mathrm{ads}} / \mathrm{H}_{\text {des }}$ region and proceeds with a rather slow increase of the current as a result of the dehydrogenation i.e. the direct path mechanism, where formate $\left(\mathrm{CHOO}^{-}\right)$, the active intermediate, is oxidized to $\mathrm{CO}_{2}$ for which no oxygen-containing species are needed [40,41]. Simultaneously, the indirect path i.e. dehydration occurs, generating $\mathrm{CO}_{\mathrm{ads}}$ and blocking Pt sites available for the direct path. Since these $\mathrm{CO}_{\text {ads }}$ can be oxidized to $\mathrm{CO}_{2}$ only by oxygen-containing species which are formed at $\mathrm{Pt}$ at higher potentials, the current reaches a maximum at $0.3 \mathrm{~V} / \mathrm{SCE}$ (noted by first peak in Fig. 7A). Upon oxidation of $\mathrm{CO}_{\mathrm{ads}}$, more Pt sites become available for FAOR and current once again increases until Pt oxide, inactive for FAOR is formed (noted by second peak in Fig. 7A). In the backward scan of Pt/C only one current maximum is recorded at potential of Pt oxide reduction after which the current decreases since $\mathrm{CO}_{\text {ads }}$ cannot be oxidized anymore at Pt surface. The ratio between currents of the first and second forward peak indicates poisoning of the surface by $\mathrm{CO}_{\mathrm{ads}}$, thus the lower ratio means more pronounced indirect path. In the case of our Pt/C catalyst this ratio is 0.47 . The potentiodynamic curve for the FAOR on PtAu/C catalyst is completely different. The reaction starts some $0.2 \mathrm{~V}$ earlier and proceeds intensively through dehydrogenation (direct path) with a poorly defined shoulder on the descending part of the curve, signifying an occurrence of the indirect path in the reaction as well (Fig. 7A). The higher ratio between direct and indirect current maximums of 1.6 indicates the domination of dehydrogenation and a significant suppression of dehydration in FAOR thus lowering the poisoning of the PtAu/C catalyst. In addition, the difference in currents between forward and backward scans is not as drastic for the PtAu/C catalyst as for Pt/C catalyst (Fig. 7B) which also confirms lower poisoning of bimetallic surfaces [42]. Since, the aim of designing a bimetallic catalyst is not only to increase activity and stability but to reduce Pt amount in the catalyst as well, mass activity of our PtAu/C in comparison to $\mathrm{Pt} / \mathrm{C}$ is presented in Fig. 8. As one can see, although PtAu/C contains notably less noble metal than Pt/C it exhibits about 2 times higher activity.

According to the literature data for PtAu systems [10,20,43], numerous factors are influenced by the reduced adsorption of $\mathrm{CO}$ as a consequence of Au presence and are more pronounced with increasing of $\mathrm{Au}$ content, which include: lower onset potential of FAOR, increase of currents of dehydrogenation path and decrease of currents of dehydration path as well as lower hysteresis between currents of forward and backward scans. In comparison to similar works in literature where Pt:Au ratios were reported to be 1:1 [10], 1:2 [43,44], 1:4 [20], the results from this study reveal that PtAu/C catalyst with only 4 at $\%$ of $\mathrm{Au}$ exhibits similar increase in activity. Investigations of FAOR on PtAu catalysts with various Pt:Au ratios by cyclic voltammetry and galvanostatic potential oscillations have disclosed that increased activity of $\mathrm{PtAu}$ is a consequence of suppressed surface poisoning by $\mathrm{CO}_{\mathrm{ads}}$, connected with a decrease in number of domains of at least three contiguous Pt atoms needed for $\mathrm{CO}_{\text {ads }}$ and an increase in smaller Pt atomic ensembles, due to Au content [10]. The PtAu/C catalyst presented in
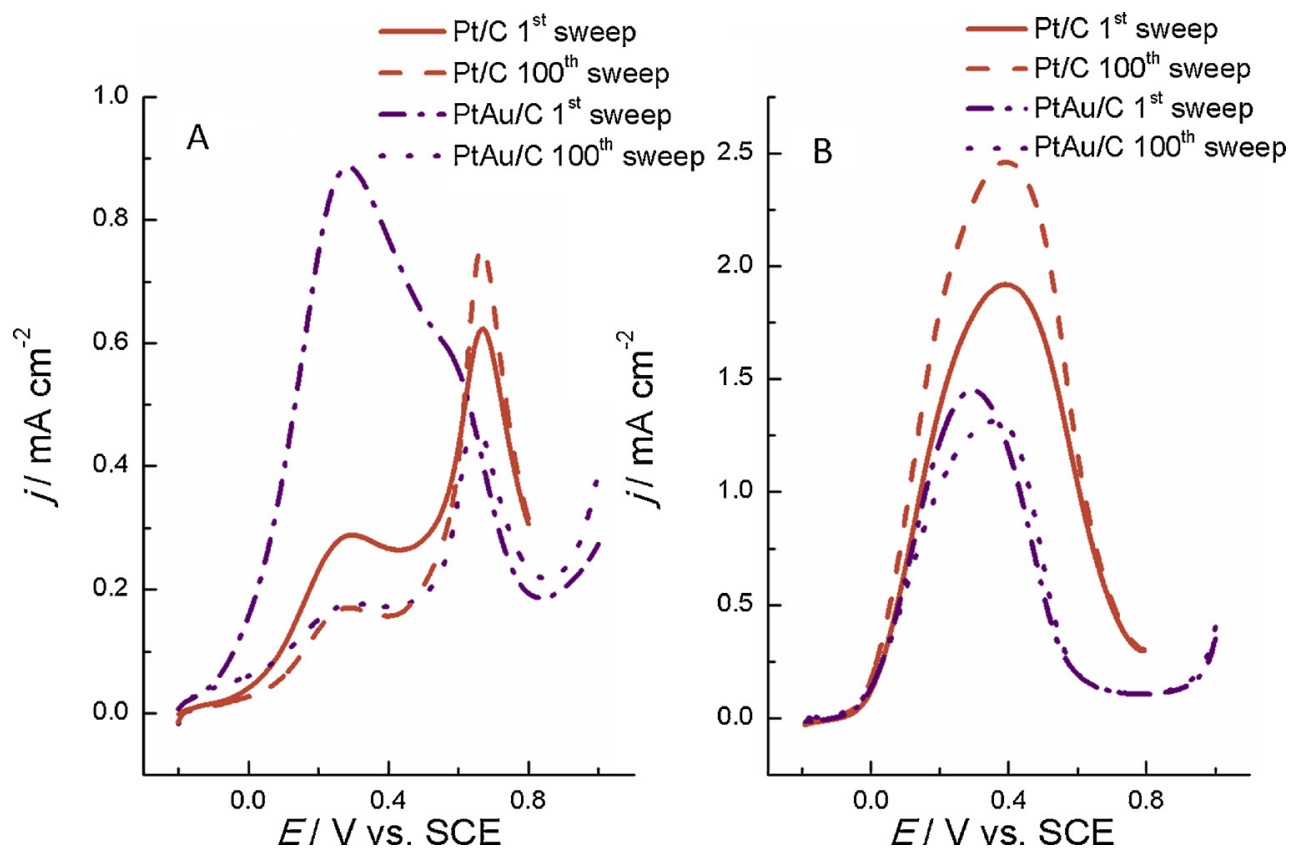

Fig. 7. Potentiodynamic (forward-A and backward-B) curves for the oxidation of $0.5 \mathrm{M} \mathrm{HCOOH}$ at as-prepared $\mathrm{Pt} / \mathrm{C}$ and $\mathrm{PtAu} / \mathrm{C}$ catalysts $(\mathrm{v}=50 \mathrm{mV} / \mathrm{s}$ ). 

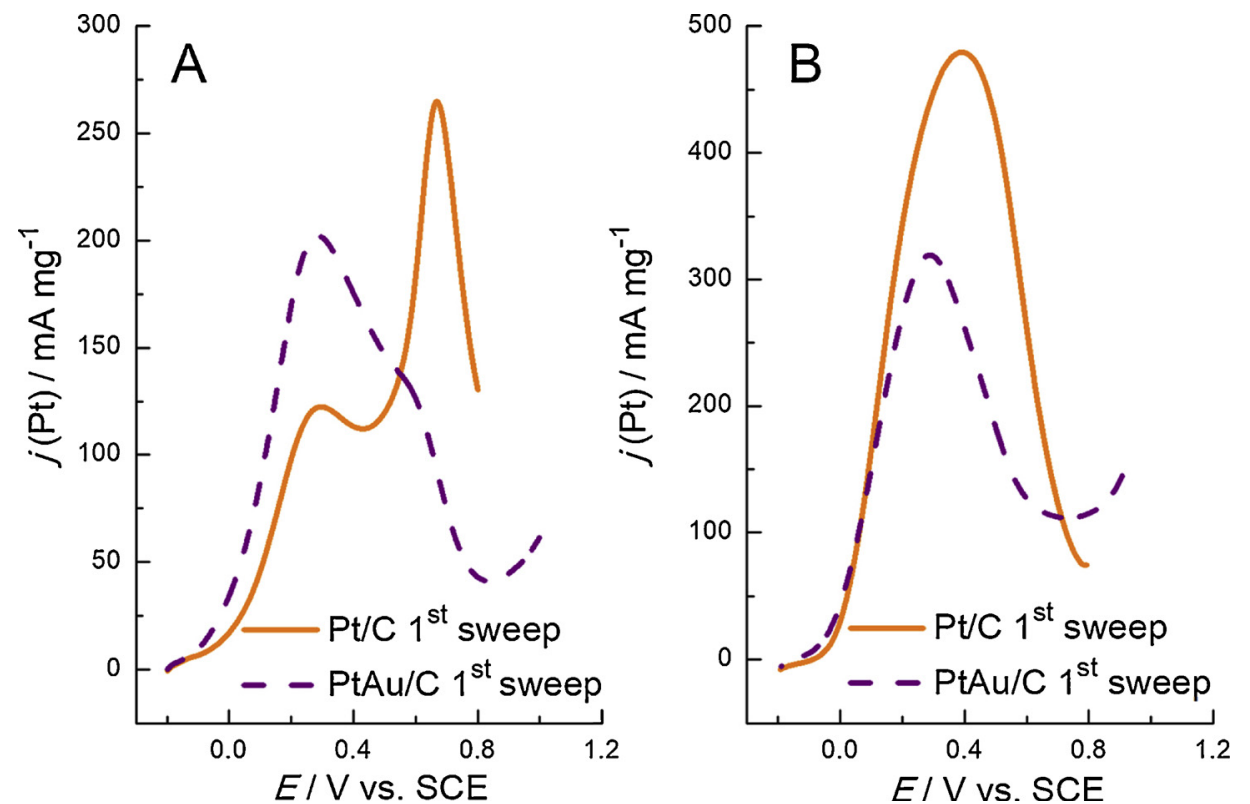

Fig. 8. Mass activity of as-prepared $\mathrm{Pt} / \mathrm{C}$ and $\mathrm{PtAu} / \mathrm{C}$ catalysts for the oxidation of $0.5 \mathrm{M} \mathrm{HCOOH}$ (forward-A and backward-B scans) (v = 50 mV/s).

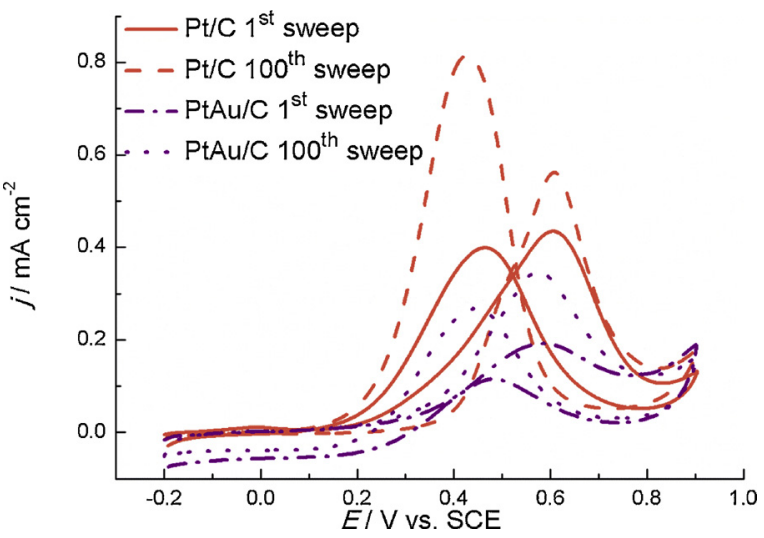

Fig. 9. Potentiodynamic curves for the oxidation of $0.5 \mathrm{M} \mathrm{CH} \mathrm{CH}_{3} \mathrm{OH}$ at as-prepared $\mathrm{Pt} / \mathrm{C}$ and $\mathrm{PtAu} / \mathrm{C}$ catalysts $(\mathrm{v}=50 \mathrm{mV} / \mathrm{s})$.

this study could possess such activity due to well-balanced interruption of continuous Pt sites by Au. Bearing in mind the extremely low $\mathrm{Au}$ content, this could be possible only by highly dispersed Au particles, very small in size. Therefore, this catalyst should have a large number of small Pt ensembles with mostly two atoms adjacent to Au and rather a small number of large Pt domains. In order to verify this assumption, we have examined the oxidation of methanol that requires at least 3 contiguous Pt atoms [14] on the PtAu/C catalyst and compared the results with the $\mathrm{Pt} / \mathrm{C}$ catalyst prepared by the same procedure which is presented in Fig. 9.

MOR occurs in numerous steps with the formation of several intermediates although two main processes in complete oxidation can be singled out: adsorption of methanol and oxidation of $\mathrm{CO}_{\mathrm{ads}}[45,46]$. Methanol begins to adsorb on Pt when enough Pt sites are free from hydrogen i.e. at potentials near $0.2 \mathrm{~V} / \mathrm{RHE}$. Adsorbed molecules undergo dehydrogenation and $\mathrm{CO}$ formed adsorbs blocking the reaction sites [47]. Oxidation of $\mathrm{CO}_{\text {ads }}$ starts when enough oxygen-containing species are produced due to a strong interaction of water with $\mathrm{Pt}$ [45]. Since water is an oxygen donor on pure Pt, oxidation of methanol to $\mathrm{CO}_{2}$ cannot begin below $0.45 \mathrm{~V} / \mathrm{RHE}$ [45]. Therefore, a catalyst for this reaction should facilitate oxidation of intermediates $\left(\mathrm{CO}_{\mathrm{ads}}\right)$ by oxygen containing species in order to form $\mathrm{CO}_{2}$. In other words, the catalyst on whose surface weak adsorption of $\mathrm{CO}$ and water dissociation at lower potentials is required. However, the $\mathrm{PtAu} / \mathrm{C}$ catalyst exhibits strong adsorption of both $\mathrm{CO}$ and $\mathrm{OH}$ species (Figs. 5 and 6) which was explained by the increase in energy of the $d$-band, induced by tensile strain and the ligand effect, enabled by a large number of Pt atoms in direct contact with Au atoms. In addition, a study of FAOR and MOR on cyanide-modified Pt(111) electrode reported that domains with at least three contiguous $\mathrm{Pt}$ atoms are necessary for the formation of $\mathrm{CO}_{\mathrm{ads}}$ (i.e. oxidation of methanol) while direct FAOR i.e. without formation of $\mathrm{CO}_{\mathrm{ads}}$ takes place at smaller ensembles [14]. The findings in this paper, for the FAOR on PtAu/C (seen in Fig. 7), imply a large number of such small $\mathrm{Pt}$ domains since the indirect path of this reaction through adsorption of $\mathrm{CO}$ is highly suppressed while direct oxidation is significantly enhanced. Therefore, the PtAu/C catalyst should be less active for MOR in comparison to the Pt/C catalyst. Indeed, the results presented in Fig. 9 demonstrate such behavior, confirming the assumption that the PtAu surface is composed of a large number of Pt ensembles, with no more than two Pt atoms in direct contact with $\mathrm{Au}$ atoms, which is possible only by very fine dispersion of a low quantity of Au.

The difference in behavior of the PtAu/C catalyst for the oxidation of formic acid and methanol is also observed during prolonged cycling i.e. long term stability measurements. The results obtained during these tests, displayed in Fig. 10 as currents at low potential region as a function of the number of cycles, have been compared with the results obtained for the $\mathrm{Pt} / \mathrm{C}$ catalyst. While for both reactions the activity of $\mathrm{Pt} / \mathrm{C}$ rapidly declines during the first 20-30 cycles after which it reaches a plateau of constant values, the $\mathrm{PtAu} / \mathrm{C}$ catalyst, for FAOR, exhibits a loss of activity in a much steadier rate by each cycle, reaching the activity of $\mathrm{Pt} / \mathrm{C}$ at the end of the test $\left(100^{\text {th }}\right.$ cycle $)$. On the other hand, for methanol oxidation $\mathrm{PtAu} / \mathrm{C}$ becomes more active during first 10 cycles after which it reaches a plateau with values remaining practically unchanged for the remainder of the test (100 cycles). Stability of the catalysts was also examined for the oxidation of formic acid by chronoamperometry (inset in Fig. 10A). Current density recorded during 1800s at a constant potential of $0.2 \mathrm{~V}$ on $\mathrm{Pt} / \mathrm{C}$ and $\mathrm{PtAu} / \mathrm{C}$ catalysts likewise long-term stability test revealed significantly slower decline in current for $\mathrm{PtAu} / \mathrm{C}$ catalyst in comparison to $\mathrm{Pt} / \mathrm{C}$ but a small difference in steady state values being still higher for $\mathrm{PtAu} / \mathrm{C}$ catalyst.

The initial increase in activity of $\mathrm{PtAu} / \mathrm{C}$ for MOR could be due to morphology changes resulting in a surface more suitable for oxidation of $\mathrm{CO}_{\mathrm{ads}}$. Since at least three contiguous Pt atoms are necessary for the 

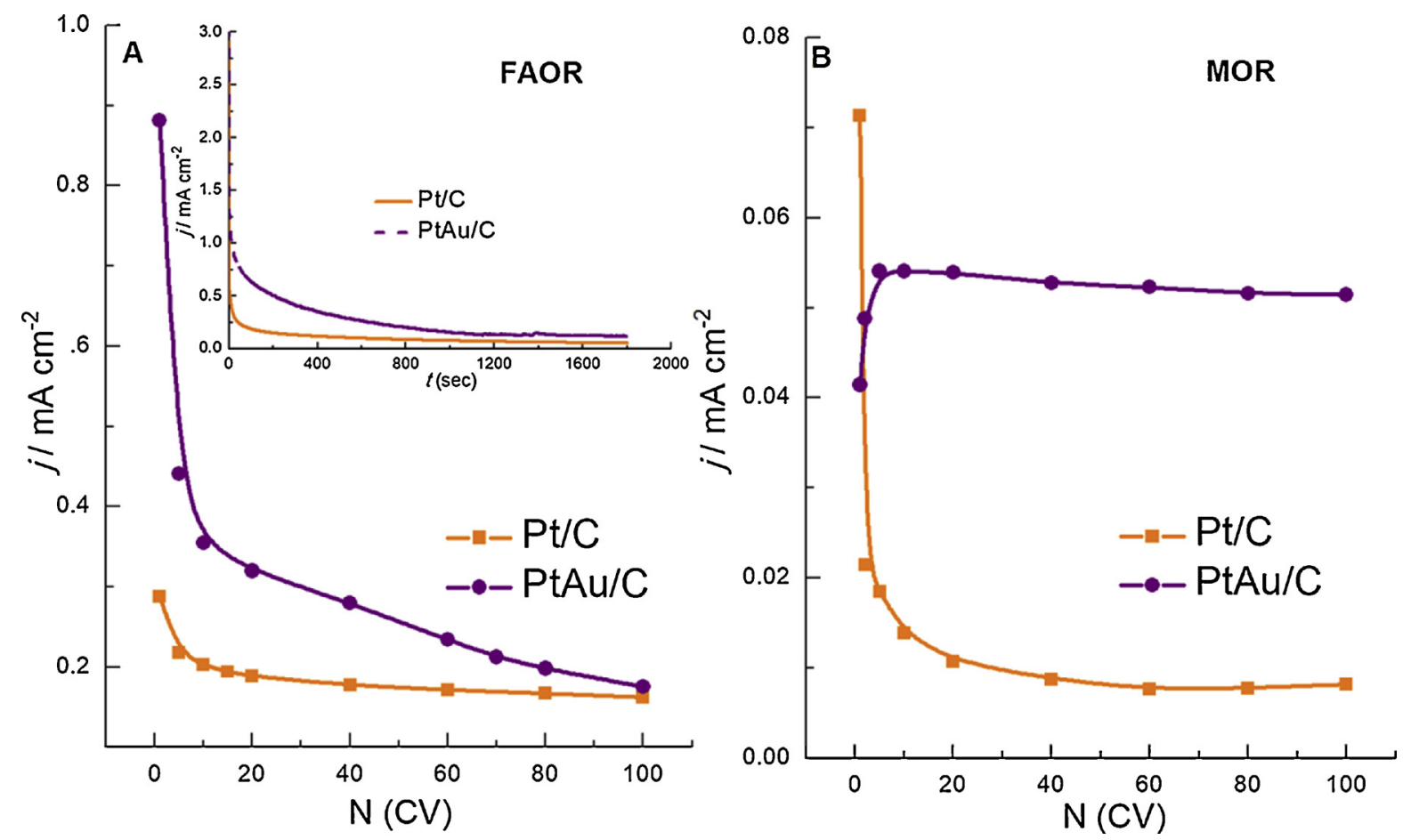

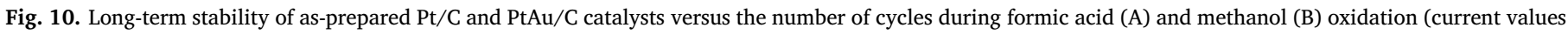

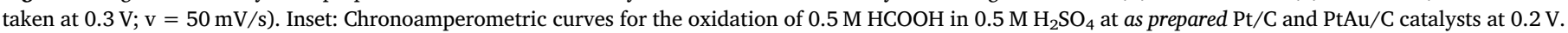

$\mathrm{CO}_{\mathrm{ads}}[14,48]$ the increase in activity of $\mathrm{PtAu} / \mathrm{C}$ for methanol oxidation upon cycling could be possible only if additional larger Pt domains are formed. This assumption is based on the results obtained from the literature, which state that the increase in Pt domains leads to enhancement in methanol oxidation $[14,33,48,49]$. It has been shown that, during cycling several types of the surface reconstruction occur, like Ostwald ripening as well as Pt dissolution and re-deposition, migration and collision of Pt particles and formation of various defects [50-52]. Larger Pt domains, with a number of defects, could be formed on the $\mathrm{PtAu} / \mathrm{C}$ catalyst which would enhance methanol oxidation but deteriorate formic acid oxidation, due to easier adsorption of $\mathrm{CO}$, and promotion of dehydration (indirect) path of the reaction. Last cycle recorded during the long-term stability test, presented in Fig. 7 as a dashed purple line, corroborates this assumption. It can be seen that currents of direct path in FAOR without $\mathrm{CO}_{\text {ads }}$ significantly decreased and the ratio between current maximum of direct and indirect path decreased from 1.6 to 0.36 , in favor of dehydration in FAOR, thus poisoning of the PtAu/C catalyst to a greater extent. However, for the $\mathrm{PtAu} / \mathrm{C}$, the reaction commences earlier than on $\mathrm{Pt} / \mathrm{C}$ and the hysteresis between forward and backward scan is still smaller implying the presence of smaller Pt ensembles on the surface as well. Last cycle recorded during the long-term stability test in methanol oxidation, presented in Fig. 9 as a dashed purple line, shows that currents have been increasing during cycling but the maximum peak currents are still lower than for $\mathrm{Pt} / \mathrm{C}$, the catalyst synthesized by the same procedure and with particles of similar size. This indicates that there is still some Au on the surface and smaller Pt domains.

\section{Conclusions}

In this study a low loading PtAu nanocatalyst supported on higharea carbon was synthesized by a water-in-oil microemulsion method and investigated for formic acid and methanol oxidation. Based on microstructural analyses performed by XRD, TEM and EDS it was discovered that the $\mathrm{PtAu} / \mathrm{C}$ catalyst particles are quasi-spherical, $\sim 4 \mathrm{~nm}$ in diameter, rather agglomerated and composed of a solid solution of
$\mathrm{Au}$ in Pt with only $\sim 4 \mathrm{at} \%$ of Au. In spite of such low Au content, the catalyst exhibits stronger binding of $\mathrm{CO}$ in comparison to $\mathrm{Pt} / \mathrm{C}$ catalyst synthesized in the same manner as a result of notable electronic effect. An essentially important fact is that in spite of this small quantity of $\mathrm{Au}$ and low PtAu loading the PtAu/C catalyst significantly enhances the direct path and suppresses the indirect path in FOAR. Such increased activity for FAOR with a favored direct path is due to the electronic and ensemble effects caused by Au presence. Small Pt ensembles, in direct contact with $\mathrm{Au}$, have been collaborated by the lower activity for methanol oxidation in comparison to the $\mathrm{Pt} / \mathrm{C}$ catalyst synthesized by the same procedure. In summary, the results obtained in this research highlight the importance of the Au dispersion on the surface of Pt over its quantity in the PtAu catalyst, for the significance of both, ensemble and electronic effects.

\section{Acknowledgements}

This work was financially supported by the Ministry of Education, Science and Technological Development, Republic of Serbia, Contract No. 172060. VVR and VRR acknowledge the Center for Nanoanalysis and Electron Microscopy (CENEM), Friedrich-Alexander-University of Erlangen-Nürnberg, Germany, where electron microscopy characterization has been performed. VRR acknowledges support by Serbian Academy of Sciences and Arts under contract \#F-141. The authors also acknowledge networking support by COST Action MP1407-STSM grant COST-STSM-MP1407-35830.

\section{Appendix A. Supplementary data}

Supplementary material related to this article can be found, in the online version, at doi:https://doi.org/10.1016/j.apcatb.2018.10.064.

\section{References}

[1] X. Yu, P.G. Pickup, Recent advances in direct formic acid fuel cells (DFAFC), J. Power Sources 182 (2008) 124-132.

[2] P.K. Babu, H.S. Kim, J.H. Chung, E. Oldfield, A. Wieckowski, Bonding and motional 
aspects of $\mathrm{CO}$ adsorbed on the surface of Pt nanoparticles decorated with Pd, J. Phys. Chem. B 108 (2004) 20228-20232.

[3] J. Solla-Gullon, V. Montiel, A. Aldaz, J. Clavilier, Electrochemical and electrocatalytic behaviour of platinum-palladium nanoparticle alloy, Electrochem. Commun. 4 (2002) 716-721.

[4] S. Stevanović, D. Tripković, V. Tripković, D. Minić, A. Gavrilović, A. Tripković, V.M. Jovanović, Insight into the effect of Sn on CO and formic acid oxidation at PtSn catalysts, J. Phys. Chem. C 118 (2014) 278-289.

[5] F. Zhou, J. Chen, Y. Wang, J. Zhang, R. Luo, X. Wei, G. Wang, R. Wang, The study of platinum-tellurium intermetallic nanoparticles for formic acid electro-oxidation, Electrochim. Acta 248 (2017) 307-312.

[6] A. De Clercq, O. Margeat, G. Sitja, C.R. Henry, S. Giorgio, Core-shell Pd-Pt nanocubes for the CO oxidation, J. Catal. 336 (2016) 33-40.

[7] M. Min, C. Kim, H. Lee, Electrocatalytic properties of platinum overgrown on various shapes of gold nanocrystals, J. Mol. Catal. A: Chem. 333 (2010) 6-10.

[8] M.B.C. de Souza, P.S. Fernández, J. Solla-Gullón, Adatom decorated shape-controlled metal nanoparticles: advanced electrocatalysts for energy conversion, Curr. Opin. Electrochem. (2018), https://doi.org/10.1016/j.coelec.2018.03.007.

[9] D.-J. Chen, Y.Y.J. Tong, The bifunctional electrocatalysis of carbon monoxide oxidation reaction, in: Klaus Wandelt (Ed.), Encyclopedia of Interfacial Chemistry, Surface Science and Electrochemistry, Elsevier, 2018, pp. 881-897.

[10] G. Cabello, R.A. Davoglioa, F.W. Hartl, J.F. Marco, E.C. Pereira, S.R. Biaggio, H. Varela, A. Cuesta, Microwave-assisted synthesis of Pt-Au nanoparticles with enhanced electrocatalytic activity for the oxidation of formic acid, Electrochim. Acta 224 (2017) 56-63.

[11] Y. Yu, K.H. Lim, J.Y. Wang, X. Wang, CO adsorption behavior on decorated Pt@Au nanoelectrocatalysts: a combined experimental and DFT theoretical calculation study, J. Phys. Chem. C116 (2012) 3841-3856.

[12] M. Arenz, V. Stamenković, B.B. Blizanac, K.J. Mayrhofer, N.M. Marković, P.N. Ross, Carbon-supported Pt-Sn electrocatalysts for the anodic oxidation of $\mathrm{H}_{2}, \mathrm{CO}$ and $\mathrm{H}_{2}$ / CO mixtures. Part II: The structure-activity relationship, J. Catal. 232 (2005) $402-410$

[13] N. Kristian, Y. Yan, X. Wang, Highly efficient submonolayer Pt decorated Au nanocatalyst for formic acid oxidation, Chem. Commun. (2008) 353-355.

[14] A. Cuesta, M. Escudero, B. Lanova, H. Baltruschat, Cyclic voltammetry, FTIRS, and DEMS study of the electrooxidation of carbon monoxide, formic acid, and methanol on cyanide-modified Pt(111) electrodes, Langmuir 25 (2009) 6500-6507.

[15] X. Yu, P.G. Pickup, Carbon supported PtBi catalysts for direct formic acid fuel cells, Electrochim. Acta 56 (2011) 4037-4043.

[16] Y. Huang, S. Zheng, X. Lin, L. Su, Y. Guo, Microwave synthesis and electrochemical performance of a $\mathrm{PtPb}$ alloy catalyst for methanol and formic acid oxidation, Electrochim. Acta 63 (2012) 346-353.

[17] M.D. Obradovic, A.V. Tripkovic, S.Lj. Gojkovic, Oxidation of carbon monoxide and formic acid on bulk and nanosized Pt-Co alloys, J. Solid State Electrochem. 16 (2012) 587-595.

[18] M.S. Cogenlia, A. Bayrakçeken Yurtcan, Catalytic activity, stability and impedance behavior of PtRu/C, PtPd/C and PtSn/C bimetallic catalysts toward methanol and formic acid oxidation, Int. J. Hydrogen Energy 43 (2018) 10698-10709.

[19] G. Chang, Z. Cai, H. Jia, Z. Zhang, X. Liu, Z. Liu, R. Zhu, Y. He, High electrocatalytic performance of a graphene-supported PtAu nanoalloy for methanol oxidation, Int. J. Hydrogen Energy 43 (2018) 12803-12810.

[20] M.D. Obradović, J.R. Rogan, B.M. Babić, A.V. Tripković, A.R.S. Gautamd, V.R. Radmilović, S.Lj. Gojković, Formic acid oxidation on Pt-Au nanoparticles: relation between the catalyst activity and the poisoning rate, J. Power Sources 197 (2012) 72-79.

[21] E. Rach, J. Heitbaum, Electrochemically induced surface modifications of Pt-Au alloy, Electrochim. Acta 32 (1987) 1173-1180.

[22] S.Zhang Y. Shao, G. Yin, Y. Lin, Facile synthesis of PtAU alloy nanoparticles with high activity for formic acid oxidation, J. Power Sources 195 (2010) 1103-1106.

[23] W.X. Chen, J.Y. Lee, Z. Liu, Microwave-assisted synthesis of carbon supported Pt nanoparticles for fuel cell applications, Chem. Commun. (2002) 2588-2589.

[24] X. Li, W.X. Chen, J. Zhao, W. Xing, Z.D. Xu, Microwave polyol synthesis of PtCNTs catalysts: effect of $\mathrm{pH}$ on particle size and electrocatalytic activity for methanol electrooxidization, Carbon 43 (2005) 2168-2174.

[25] X. Hu, C. Lin, L. Wei, C. Hong, Y. Zhang, N. Zhuang, High electrocatalytic performance of graphene nanoribbon supported PtAu nanoalloy for direct ethanol fuel cell and theoretical analysis of anti-CO poisoning, Electrochim. Acta 187 (2016) $560-566$.

[26] D.N. Oko, J.M. Zhang, S. Garbarino, M. Chaker, D.L. Ma, A.C. Tavares, D. Guay, Formic acid electro-oxidation at PtAu alloyed nanoparticles synthesized by pulsed laser ablation in liquids, J. Power Sources 248 (2014) 273-282.

[27] M.N. Krstajić Pajić, S.I. Stevanović, V.V. Radmilović, A. Gavrilović-Wohlmuther, V.R. Radmilović, S.Lj. Gojković, V.M. Jovanović, Shape evolution of carbon supported Pt nanoparticles: from synthesis to application, App. Catal. B: Environ. 196 (2016) 174-184.

[28] A.X.S. Bruker, TOPAS V2.1: General Profile and Structure Analysis Software for Powder Diffraction Data, User Manual, Bruker AXS, Karlsruhe, Germany, 2003.

[29] S. Tanuma, C.J. Powell, D.R. Penn, Calculations of electron inelastic mean free paths. V.DAta for 14 organic compounds over the $50-2000 \mathrm{eV}$ range, Surf. Interface Anal. 21 (1993) 165-176.

[30] I.-S. Park, K.-S. Lee, J.-H. Choi, H.-Y. Park, Y.-E. Sung, Surface structure of Ptmodified Au nanoparticles and electrocatalytic activity in formic acid electro-oxidation, J. Phys. Chem. C 111 (2007) 19126-19133.

[31] K. Kinoshita, J.T. Lundquist, P. Stonehart, Potential cycling effects on platinum electrocatalyst surfaces, J. Electroanal. Chem. 48 (1973) 157-166.

[32] J. Solla-Gullon, P. Rodriguez, E. Herrero, A. Aldaz, J.M. Feliu, Surface characterization of platinum electrodes, Phys. Chem. Chem. Phys. 10 (2008) 1359-1373.

[33] S. Kumar, S. Zou, Electrooxidation of carbon monoxide and methanol on platinumoverlayer-coated gold nanoparticles: effect of film thickness, Langmuir 23 (2007) 7365-7371.

[34] B. Hammer, Y. Morikawa, J.K. Nørskov, CO chemisorption at metal surfaces and overlayers, Phys. Rev. Lett. 76 (1996) 2142-2144.

[35] J.R. Kitchin, J.K. Nørskov, M.A. Barteau, J.G. Chen, Role of strain and ligand effects in the modification of the electronic and chemical properties of bimetallic surfaces, Phys. Rev. Lett. 96 (1-4) (2004) 156801.

[36] G. Chen, Y. Li, D. Wang, L. Zheng, G. You, C.-J. Zhong, L. Yang, F. Cai, J. Cai, B.H. Chen, Carbon-supported PtAu alloy nanoparticle catalysts for enhanced electrocatalytic oxidation of formic acid, J. Power Sources 196 (2011) 8323-8330.

[37] M. Yina, Y. Huanga, Qi. Lva, L. Liang, J. Liao, C. Liu, W. Xinga, Improved direct electrooxidation of formic acid by increasing Au fraction on the surface of PtAu alloy catalyst with heat treatment, Electrochim. Acta 58 (2011) 6-11.

[38] M. Arenz, K.J.J. Mayrhofer, V. Stamenkovic, B.B. Blizanac, T. Tomoyuki, P.N. Ross, N.M. Markovic, The effect of the particle size on the kinetics of $\mathrm{CO}$ electrooxidation on high surface area Pt catalysts, J. Am. Chem. Soc. 127 (2005) 6819-6829.

[39] M.J.S. Farias, C. Busó-Rogero, F.J. Vidal-Iglesias, J. Solla-Gullón, G.A. Camara, J.M. Feliu, Mobility and oxidation of adsorbed CO on shape-controlled Pt nanoparticles in acidic medium, Langmuir 33 (2017) 865-871.

[40] A. Miki, S. Ye, M. Osawa, Surface-enhanced IR absorption on platinum nanoparticles: an application to real-time monitoring of electrocatalytic reactions, Chem. Commun. (2002) 1500-1501.

[41] S.G. Sun, J. Clavilier, A. Bewick, The mechanism of electrocatalytic oxidation of formic acid on Pt (100) and Pt (111) in sulphuric acid solution: an emirs study, J. Electroanal. Chem. Interfacial Electrochem. 240 (1988) 1-376.

[42] A. Lopez-Cudero, F.J. Vidal-Iglesias, J. Solla-Gullon, E. Herreo, A. Aldaz, J.M. Feliu, Formic acid electrooxidation on Bi-modified Pt (110) single crystal electrodes, J. Electroanal. Chem. 637 (2009) 63-71.

[43] N. Kristian, Y. Yu, P. Gunawan, R. Xu, W. Deng, X. Liu, X. Wang, Controlled synthesis of Pt-decorated Au nanostructure and its promoted activity toward formic acid electro-oxidation, Electrochim. Acta 54 (2009) 4916-4924.

[44] Y. Han, Y. Ouyang, Z. Xie, J. Chen, F. Chang, G. Yu, Controlled growth of Pt-Au nanowires and their performance for formic acid electrooxidation, J. Mater. Sci. Technol. 32 (2016) 639-645.

[45] T. Iwasita, Electrocatalysis of methanol oxidation, Electrochim. Acta 47 (2002) 3663-3674.

[46] M.W. Breiter, Electrochemical Processes in Fuel Cells, Springer-Verlag, Berlin, 1969.

[47] B. Beden, F. Hahn, C. Lamy, J.M. Leger, N.R. Tacconi, R.O. Lezna, A.J. Arvia, Chemisorption of methanol on different platinum electrodes (smooth and rough polycrystalline, monocrystalline, and preferentially oriented), as studied by EMIRS, J. Electroanal. Chem. 261 (1989) 401-408.

[48] B.I. Podlovchenko, Yu.M. Maksimov, Peculiarities in the electrocatalytic behavior of ultralow platinum deposits on gold synthesized by galvanic displacement, J. Electroanal. Chem. 756 (2015) 140-146.

[49] R. Feng, M. Li, J. Liu, Synthesis of core-shell Au@Pt nanoparticles supported on Vulcan XC-72 carbon and their electrocatalytic activities for methanol oxidation, Colloids Surf. A: Physicochem. Eng. Aspects 406 (2012) 6-12.

[50] Q. Xu, E. Kreidler, D.O. Wipf, T. He, In situ electrochemical STM study of potentialinduced coarsening and corrosion of platinum nanocrystals, J. Electrochem. Soc 155 (2008) B228-B231.

[51] Y. Sugawara, A.P. Yadav, A. Nishikata, T. Tsuru, Dissolution and surface area loss of platinum nanoparticles under potential cycling, J. Electroanal. Chem 662 (2011) 379-383.

[52] K. Hartl, M. Nesselberger, K.J.J. Mayrhofer, S. Kunz, F.F. Schweinberger, G.H. Kwon, M. Hanzlik, U. Heiz, M. Arenz, Electrochemically induced nanocluster migration, Electrochim. Acta 56 (2010) 810-816. 